\title{
Reasoning Behaviors of Mathematics Difficulties Students in Solving Multiplication Integers
}

\author{
Fitri Tri Hana Padang, Yusuf Fuad, and Rooselyna Ekawati \\ Program Pascasarjana Department of Mathematics, Universitas Negeri Surabaya, Surabaya, East Java, Indonesia \\ fitripadang16070785007@mhs.unesa.ac.id
}

\begin{abstract}
Behavior is an action to be performed, in learning behavioral math can be interpreted as a way of student action when solving problems. Reasoning is one part of the thinking process of students to drawing aconclusions from a problem. Reasoning behavior studentshas been attracted many researchers to assess the development of students' mathematical thinking. in problem solving that ends in conclusion. The ability of reasoning acts an important role for students to learn mathematics. The purpose of this study is to investigate reasoning behaviors of the grade $6^{\text {th }}$ students with mathematical difficulties in solving problems of integer multiplication operations. The sample of this qualitative studywas the $5^{\text {th }}$ grade students in Madiun, East Java. All students were given the multiplication test from which students with mathematical difficulties were indicated. Furthermore, three volunteer students were selected as the research subjects, and were interviewed based on their answer. Two students have difficulties when word problems solving and one subject has problems when in the problem solving stage. Whensolving the word problems, two subjects were not able to describe the known and the way to determine the solution. The subject with low ability had no an idea how to solve the problem. The third subject had implementedan incorrect concepts in solving the problems. Eventhough take more time, by applying both a structured-scaffolding and learning methods that fit the problem can be overcome. This study emphasizes that lack understanding of mathematical concepts and reasoning abilities could be handled for any MD's student by implementing the structured-scaffolding based on visualized media
\end{abstract}

Keywords- Reasoning Behavior, Mahematics Difficulties, Problem Solving

\section{INTRODUCTION}

Integers are important in our daily lives. At the base level, integers are defined as numbers represented by negative integer pairs $\{\ldots,-3,-2,-1\}$, zero $(0)$, and positive integers $\{1,2,3, \ldots\}$. The integer of the complete notation is I, and the integer component is $\{\ldots,-3,-2,-1,0,1,2,3, \ldots\}$. In the integer line, position the positive integer to the right to the right of zero, while the negative integer to the left is left zero [1].

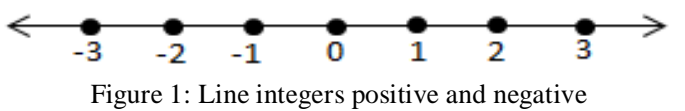

At the basic level, there are four operations on integers, called basic arithmetic, such as: addition, subtraction, multiplication and division $[1,2]$. It is important for students at the elementary level to have good skills in arithmetic, to be able to follow the math learning at the next level [3]. In addition, basic arithmetic can be used in everyday life, such as in sale and purchase transactions, traders can calculate the profit and loss of sales of goods by using basic arithmetic.

It is known from the four count operations that must be controlled by students, one of which is a multiplication operation. Multiplication surgery is the most important count operation to be studied in basic education [6]. The multiplication in integer operation is defined as the recurring sum with a fixed sum [13], symbolized by " $\mathrm{x}$ ". Based on a survey conducted by researchers at one elementary school in Madiun, it is known that the application of grade 4 basic multiplication until 6 is still very lacking. Likewise from a survey conducted by a researcher in California. The survey results suggest that most high school students in California have difficulty in completing quadratic multiplication, fractional multiplication and other multiplicity related material [4]. The main causes of difficulty are lack of understanding of the basic concepts of student multiplication, as well as the lack of reasoning in solving student problems. Especially in students of Mathematics Difficulties (MD). Often grade 3 to 6 grade MD students make mistakes on multidigit multiplication counts [6]. Most MD students rely solely on memorizing 1-10 without knowing exactly how to calculate, such as when counting with double-digit and triple-digit duplicates, errors occur because it is not appropriate to find the value of units, tens and hundreds, so that the final results or answers obtained by students are wrong .

Why do students have to master the understanding of concepts rather than just memorizing? because in mathematics if just relying on the ability to memorize it alone can be a major factor behind the learning difficulties of mathematics [7]. Therefore it is necessary to understand the basic concept of good. The ability of reasoning plays an important role for students to learn math. Generalize ideas and solutions strategies for applying mathematical reasoning to new situations and ploblems [9]. Behavior is essentially observable physical activity [13], in learning mathematical behavior can be interpreted as a way of student action when solving 
problems. Reasoning is one part of the thinking process of students to draw conclusions from a problem. So it can be said student's reasoning behavior is a process of thinking students to determine how to solve problems that ended with the conclusion. Based on this definition, students' reasoning behavior can be known from the way students solve problems. From the above problems, the question raised by researchers in this study is "How do students understand the problem? and How is the student's reasoning behavior in solving the problem?".

\section{METHOD}

The sample of this research is 5 th grade students of SDN Pajar, Madiun, Indonesia. This class consists of 12 female students and 8 male students. To get a research subject, all students are given 10 questions on math skills test (TKM) and 5 questions on multiplication test (TP), researchers will choose subjects who have a test score below the standard of minimum completeness criteria for learning mathematics in Indonesia [15], and the score will be matched with student report score in four semesters previous. Three volunteer students were selected as research subjects, all three having different difficulties in multiplication. One subject had difficulty in the problem-solving test TP, and two subjects had difficulty understanding and solving word problems in test TP. Semistructured interviews are conducted for the subject's thought process or preocess reasoning in the writing test of equations. Table 1 shows the Indicator of reasoning mathematics in problem solving mathematics.

TABLE I. INDICATOR OF REASONING MATHEMATICS IN PROBLEM SOLVING MATHEMATICS

\begin{tabular}{|l|l|}
\hline $\begin{array}{l}\text { Process } \\
\text { Problem } \\
\text { Solving }\end{array}$ & Reasoning Indicator \\
\hline $\begin{array}{l}\text { Understand the } \\
\text { Problem }\end{array}$ & $\begin{array}{l}\text { 1. } \\
\text { 2tudent MD can understand with the } \\
\text { multiplication problem. }\end{array}$ \\
\hline Student MD can explain found set of problems. \\
3. $\begin{array}{l}\text { Student MD can devise details of known and } \\
\text { asked in the problems. }\end{array}$ \\
\hline $\begin{array}{l}\text { Carry Out the } \\
\text { Plan }\end{array}$ & 1. $\begin{array}{l}\text { Student MD can devise a plan solution of the } \\
\text { multiplication problem } \\
\text { Student MD can predicted the answer of the } \\
\text { multiplication problem }\end{array}$ \\
\hline Look Back & 2. $\begin{array}{l}\text { Student MD can use data from the } \\
\text { Student MD can be process of devise a planing } \\
\text { solution }\end{array}$ \\
\hline
\end{tabular}

\section{RESULT AND DISCUSSION}

The first analysis of the provision of multiplication test for all students of class 5 . The results obtained from the five questions given are:
TABLE II: THE ANSWER OF ALL STUDENT IN MLTIPLICATION TASK

\begin{tabular}{ccc}
\hline Number & Conclution True & Conclution False \\
\hline $\mathbf{1}$ & $18 \mathrm{p}$ & $2 \mathrm{p}$ \\
$\mathbf{2}$ & $20 \mathrm{p}$ & $0 \mathrm{p}$ \\
$\mathbf{3}$ & $1 \mathrm{p}$ & $19 \mathrm{p}$ \\
$\mathbf{4}$ & $9 \mathrm{p}$ & $11 \mathrm{p}$ \\
$\mathbf{5}$ & $2 \mathrm{p}$ & $18 \mathrm{p}$ \\
\hline
\end{tabular}

Exp: $p=$ person

In the data, it can be seen that many students show errors in numbers three, four, and five in the form of word questions. There are several types of errors indicated by students, such as: an error resolution strategy, an error in the problem-solving process that results in incorrect results from the final answer obtained. Below will be explained in detail the errors made by the three subjects of research.

\section{A. Behavior reasoning by Student 1}

The first student shows an error in the problem solving stage (Figure 2). When calculating multidigit multiplication, the student shows misplaced value of place in the calculation process. That should be the value of tens, students put on the unit value, as well as with the value of hundreds, students put on the value of tens. The final result obtained by the students was wrong. In the interview will be known behavior of students' reasoning.

Q : Can you understand the problem easily?

S1 : Quite difficult, but can understand with the problem.

Q : How do you determine a problem-solving strategy?

$\mathrm{S} 1$ : find out what information is asked and known first

$\mathrm{Q}$ : Can you tell me how to solve the problem, and what constraints do you experience?

S1: yes, both numbers are known to be multiplied instantly. Difficult calculating the multiplication of the number of thousands. Often forget mine.

From further interviews it is known that the main obstacle is multidigit multiplication calculation. In further interviews, subject 1 tells the researcher that he has been able to complete the multiplication easily if it is a singledigit multiplication, using a multiplication of 1-10 memorials to help him.
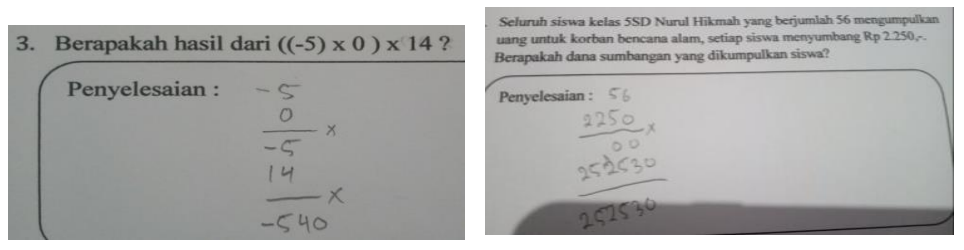

Figure 2: The answer of Student 1 in Multiplication Task 
B. Behavior reasoning by student 2 and 3

Unlike student 1 , student 2 and 3 will be able to solve the problem if the given problem is routine. As in the number 1 and 2 questions easily students can solve them, but on the number 3, 4 and 5 students do not show the completion process at all (Figure $3 \& \mathbf{4}$ ). Students simply write down the answers without writing down the process of counting them.
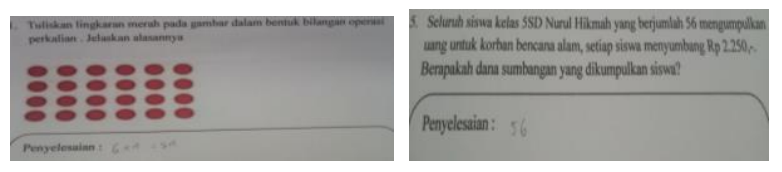

Figure 3: The Answer of Student 2 in Multiplication Task
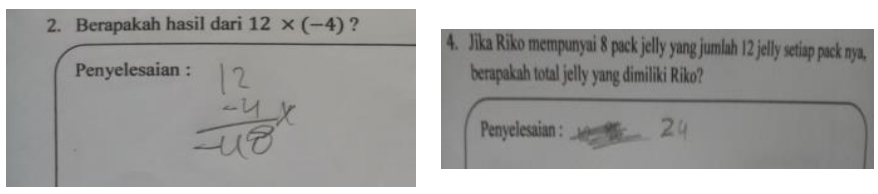

Figure 4: The Answer of Student 3 in Multiplication Task

In the interview below will be known why the students just answer limitedly:

Q: Can you understand the problem easily?

S2: Not easy for numbers 3 and 5, complicated.

S3: No

Q: How do you determine a problem-solving strategy?

S2: Read it over and over again

S3: Read only

Q: Can you tell me how to solve the problem, and what constraints do you experience?

S2: number 4 is multiplied by all, if number 3 and 5 do not know how.

S3: Do not understand why, so I do not know how to solve it.

The reasoning behavior shown by students 2 and 3 of the interview results is known if students have low ability to understand the problem. How to answer students who provide answers without using a settlement strategy can also indicate the low ability of students to understand and solve word problems. From further interviews, when getting word problems, the second and third students have difficulty to understand the problem, which is caused by lazy to read a long problem is the most important obstacle. Below we will show analysis of student answer result based on assessment indicator.

TABLE III. THE ANSWER STUDENT ACCORDING TO INDICATOR

\begin{tabular}{|c|c|c|c|c|c|}
\hline & & $\begin{array}{c}\text { Understand } \\
\text { the } \\
\text { Problem }\end{array}$ & $\begin{array}{c}\text { Devise } \\
\text { a Plan }\end{array}$ & $\begin{array}{c}\text { Carry } \\
\text { Out the } \\
\text { Plan }\end{array}$ & $\begin{array}{c}\text { Look } \\
\text { Back }\end{array}$ \\
\hline \multirow{2}{*}{1} & S1 & Yes & Yes & Yes & Yes \\
\cline { 2 - 6 } & S2 & Yes & Yes & Yes & Yes \\
\cline { 2 - 6 } & S3 & Yes & Yes & Yes & Yes \\
\hline
\end{tabular}

TABLE III. CONT.

\begin{tabular}{|c|c|c|c|c|c|}
\hline \multirow{4}{*}{2} & $\begin{array}{c}\text { Understand } \\
\text { the } \\
\text { Problem }\end{array}$ & $\begin{array}{c}\text { Devise } \\
\text { a Plan }\end{array}$ & $\begin{array}{c}\text { Carry } \\
\text { Out the } \\
\text { Plan }\end{array}$ & $\begin{array}{c}\text { Look } \\
\text { Back }\end{array}$ \\
\hline \multirow{4}{*}{2} & S1 & Yes & Yes & Yes & Yes \\
\cline { 2 - 6 } & S2 & Yes & Yes & No & No \\
\cline { 2 - 6 } & S3 & Yes & Yes & Yes & Yes \\
\hline \multirow{3}{*}{3} & S1 & Yes & Yes & Yes & No \\
\cline { 2 - 6 } & S2 & No & No & No & No \\
\cline { 2 - 6 } & S3 & No & No & No & No \\
\hline \multirow{4}{*}{4} & S1 & Yes & Yes & Yes & No \\
\cline { 2 - 6 } & S2 & No & No & No & No \\
\cline { 2 - 6 } & S3 & No & No & No & No \\
\hline \multirow{3}{*}{5} & S1 & Yes & Yes & Yes & No \\
\cline { 2 - 6 } & S2 & No & No & No & No \\
\cline { 2 - 6 } & S3 & No & No & No & No \\
\hline
\end{tabular}

According to the table above, the second and third students show the low reasoning of students in understanding and determining the way or strategy to solve the problem (behavior), and the creativity of students to answer questions is still lower than the first student. Not only the behavior is still weak, the results of the three students also show that most of the students' reasoning ability in solving problems is still very weak. This can affect the final outcome and the value obtained by the student. What can be concluded from the above analysis results is, the lower the students' reasoning ability then the end result will be low, and vice versa, if the students have good reasoning ability, then most likely will get high end result.

The resultsof this research represent that each student has a variety of reasoning and reasoning skills to solve a given problem. Students with good reasoning ability can easily solve problems $[8,9]$. However, the results obtained from this study indicate, students who are able to understand the problem well not necessarily can get the right results. As shown by the first student, it can understand the problem but at the completion stage indicates an error due to lack of understanding of the basic concept of multiplication and rely solely on rote. The strategy of memorization that has been applied can be a factor of student's difficulty in mathematics. Students are said to understand the concept well, can be seen from the workmanship and the correct calculation [10,11]. Meanwhile, the second and third students are only able to solve routine problems. When getting word problems students just read it without understanding the problem. In addition, students' inability to solve word problems can be caused by a lack of student skills in determining the problem solving strategy or strategy $[4,6,12]$.

\section{CONCLUSion}

The lack of reasoning ability and the lack of skills of students to determine the way or strategy in solving problems can affect student learning outcomes. For students of Mathematics Difficulties (MD) in order to follow the learning well requires special handling or methods and learning models tailored to the material that will be accepted students. So it can be said that the creativity of teachers in the learning and 
learning process can help students to get good learning outcomes.

\section{ACKNOWLEDGEMENT}

This research here in was support by SD Negeri 1 Pajaran, especially for $5^{\text {th }}$ grade as a 3 students in this class who helped this research

\section{REFERENCES}

[1] G. L. Musser, B. E. Peterson, and W. F. Burger, Mathematics For Elementary Teachers, A Contemporary Approach, 10th Editioan, 2013.

[2] The Indonesian Ministry of Education and culture, Regulation of the Minidstries of Education and Culture Number 24, Jakarta: State Secretariat, 2016.

[3] J. Hiebert, What research says about NCTM standards. In: Kilpatrick J, Martin W G, Schifter D, editors. A research companion to principles and standards for school mathematics, Reston (VA): National Council of Teachers of Mathematics, 2013, p.5-23.

[4] E. S. Tillema, "A power of meaning multiplication: Three eight graders' solutions of Cartesian product problems", The Journal of Mathematics Behavior, vol. 32, no. 3, pp. 331-352, 2006.

[5] F. J. Gardella, Introduction difficult mathematics topic in the elementary classroom: A teacher's guide to initial lessons, New York: Routledge Taylor \& Francis Group, 2009.

[6] S. H. Van der Ven, M. Straatemeier, B. R. Jansen, S. Klinkenberg, H. L. Van der Mass, "Learnng multiplication: An integrated analysis of the multiplication ability of primary school children and the difficulty of single digit and multidigit multiplication problems", Learning and individual Differences, vol. 43, pp. 48-62, 2015.
[7] J. Lithner, "A research framework for creative and imitative reasoning", Educational Studies in Mathematics, vol. 67, no. 3, pp. 255-276, 2008

[8] D. F. Lohman and J. M. Lakin, Reasoning and Intelligence, Handbook of intelligence, 2009, pp. 1-47.

[9] E. Y. Loong, A. B. Leicha, and S. Herbert, "Primary School Teachers; Perceptions of Mathematical Reasoning", vol. 56, pp. 11-30, 2015.

[10] B. R. Bryant, D. P. Bryant, J. Porterfield, M. S. Dennis, T. Falcomata, C. Valentine, C. Brewer, and K. Bell, "The Effect of a Tier 3 Intervention on the Mathematics Performance of Second Grade Students With Severe Mathematics Difficulties", Journal of Learning Disabilities, pp. 1-13, 2014.

[11] A. K. Jitendra, D. N. Dupuis, J. R. Star, and M. C. Rodriguez, "The Effect of Schema-Based Instruction on the Propotional Thinking of Students With Mathematics Difficulties With and Without Reading Difficulties", Journal of Learning Disabilities, pp. 1-14, 2014.

[12] K. Larsson, K. Pettersson, and P. Andrews, "Students' conceptualisations of multiplication as repeated addition or equal groups in relation to multi-digit and decimal numbers", Journal of Mathematical Behaviour, vol. 48, pp. 1-13, 2017.

[13] J. A. Walle, K. S. Karp, and J. M. Bay-Williams, Elementary and Middle School Mathematics Teaching Developmentally, United State of America: Pearson, 2013.

[14] J. P. Bishop, L. L. Lamb, R. A. Philipp, I. Whitacre, B. P. Schappelle, and M. L. Lewis, "Obstacles and Affordances for Integer Reasoning: An Analysis of Children's Thinking and the History of Mathematics", Journal for Research in Mathematics Education, vol. 45, no. 1, pp. 1961, 2014.

[15] The Indonesian Ministry of Education and culture, Regulation of the Minidstries of Education and Culture Number 22, Jakarta: State Secretariat, 2016. 